Research Article

Jorge I. Valdovinos*

Transparency as Ideology, Ideology as Transparency: Towards a Critique of the Meta-aesthetics of Neoliberal Hegemony

https://doi.org/10.1515/culture-2018-0059

Received June 15, 2018; accepted November 18, 2018

\begin{abstract}
Along with the increasing commodification of all aspects of culture and the persistent aestheticisation of everyday life under late capitalism, there is an equally increasing longing for objectivity, immediacy, and trust. As the mediation of our everyday experiences augments, a generalised feeling of mistrust in institutions reigns; the sense of a need to bypass them increases, and the call for more "transparency" intensifies. As transparency manages to bypass critical examination, the term becomes a source of tacit social consensus. This paper argues that the proliferation of contemporary discourses favouring transparency has become one of the fundamental vehicles for the legitimation of neoliberal hegemony, due to transparency's own conceptual structure-a formula with a particularly sharp capacity for translating structures of power into structures of feeling. While the ideology of transparency promises a movement towards the abolition of unequal flows of information at the basis of relations of power and exploitation, it simultaneously sustains a regime of hyper-visibility based on asymmetrical mechanisms of accountability for the sake of profit. The solution is not "more" transparency or "better" information, but to critically examine the emancipatory potential of transparency at the conceptual level, inspecting the architecture that supports its parasitic logic.
\end{abstract}

Keywords: ideology, transparency, neoliberalism

\title{
Introduction
}

One of the dominant neoliberal responses to the crises that our global economy has experienced in the last few decades is a call for "more transparency." The extensive, repetitive, and adamant nature of this call makes it possible to treat transparency as one of the cornerstones in "the rhetorical foundation of the new international financial architecture" (Best ix). In turn, this rhetorical foundation is part of a broader ideological formation that ties together a series of widely held beliefs, one of the most central of which is the view that asymmetrical information is disastrous for the correct functioning of markets: as argued, for instance, by Akerlof's famous "Market for lemons" thesis. On one level this discursive formation fuels requests for more transparency, often in the form of technical solutions like improved monitoring or measurement processes. Yet on another level, it preserves the belief in the existence of a spontaneous and "natural" regulatory mechanism animating the market-a mechanism famously described by economists via the "invisible" hand metaphor. In other words: we need to have access to more information about the market, but since the market is driven by the emergent order of the total sum of distributed knowledge, any political efforts to use this information for the purposes of planning and regulation would not only be pointless, but even detrimental. In the meantime, algorithmically-assisted speculation and high-frequency

*Corresponding author: Jorge I. Valdovinos, The University of Sydney, E-mail: jorge.valdovinos@sydney.edu.au 
trading have slowly naturalised a shift from concerns about the "real" economy, to concerns about windows of opportunity for gaming the system (Pasquale 130). What I would like to draw attention to is the fact that the various problems emerging from this apparently self-contradictory logic are not so much the result of a mistaken or manipulative use of the term transparency. Rather, they are transparency itself. They express the internal contradiction of the conceptual metaphor animating this term, one that is particularly susceptible to being put in the service of ideological formations. This contradiction allows transparency to be complicit in a process of value-creation that reinforces existing power dynamics while effacing the social relations that sustain it, shielding the existing market order from any attempts at political intervention. And this conceptual operation, I argue, extends well beyond the discourses of global finance.

My central argument is that, although the term transparency has gained a prominent place in discourses that promise to disclose, inform, and emancipate, the conceptual structure in which its semantic operations rest actually facilitates the perpetuation of information asymmetries and the legitimation of neoliberal hegemony. The solution, I will argue, is therefore not "more" transparency or "better" information, but to critically examine the emancipatory potential of transparency at the conceptual level. Here, I am much more interested in transparency's premises than in its promises: What are the conceptual foundations in which the discursive uses of transparency guiding these implementations are based on, and what grounds are there for treating them as ideological? My point of departure here involves considering transparency's alliance between ideology and aesthetics as a symptom of a broader historical shift in the very operation of power: "The aesthetic ... marks a historic shift from what we might now, in Gramscian terms, call coercion to hegemony, ruling and informing our sensuous life from within while allowing it to thrive in all its relative autonomy" (Eagleton 328). A critique formulated in these terms goes beyond traditional attempts at demystifying persuasion by exposing ideology as "distorted" reality, and instead goes closer to Baudrillard's description of a movement towards the "last stage of the social relation" (Simulacra and Simulation 39), a meta-stability of the hegemonic system which he described as a vanishing of the gap between traditionally separated poles of reference, the contraction of cause and effect, and the "indifferentiation of the active and the passive" (31). In such a scenario, the "generalized deterrence of chance, of accident ... [is] doomed to the descriptive transparency of mechanisms of information" (35), a domestication of the event brought by "forced confession in the guise of freedom of expression" (42). Here, the traditional gestures of debunking propaganda or exposing the ruses of publicity are not only inefficient but counterproductive: they are simply accomplices of the system.

In order to advance this line of argument, in the following sections, I will explore some aspects of this line of enquiry, with an emphasis on the aesthetic connections between the concept of "transparency" and the broader notion of "ideology." In doing so, I am aware that I am addressing transparency in a way that departs from its standard usage. Here, I am not interested in developing a conclusive taxonomy of its usesrather, my main interest has to do with understanding the complex relationship between transparency as a conceptual building-block, and transparency as a predominant cultural value, or put differently, to theorise how it might be that specific modes of thinking via the concept "transparency" can inflect wider cultural perceptions of what transparency "is," and how we should "feel" about it. Put differently: how can it be that a de-mythologisation of claims to objectivity in one level, is able to nonetheless re-instate a fetishisation of authenticity on another level, and even bring about new forms of essentialism? I believe this relationship constitutes a vital and a largely under-examined social aspect of our lives under late capitalism, as well as a fruitful approach for the examination of a variety of contemporary discourses, including those of free markets, governance, democracy, surveillance, media, and post-truth.

\section{A New Semantic Hegemony}

Along with the discourses of global finance, other recent examples of the relevance that transparency has attained for contemporary debates include disclosure platforms, mass surveillance, and the so-called frictionless economy. It is used to mediate tensions between scandals and new digital iterations of the fourth estate (e.g. WikiLeaks), to polarise opinions between those that demand truth in the form of freedom of information, and those that justify secrecy on the grounds of national security), (e.g. PRISM and the 
Five Eyes alliance); and to legitimise the pervasive algorithmic mediation of our everyday practices in the name of convenience (e.g. hyper-customised consumer recommendations) and privacy (e.g. the collection, use and ownership of personal data), just to name a few. As Alloa and Thomä have recently pointed out, transparency's pervasiveness has acquired an aura of general desirability that has overshadowed attempts to challenge the term or mobilise it in the service of critique.

This semantic hegemony has allowed it to become "the ultimate consensual value of our time" (2), and even the "new imperative of a supposedly post-ideological age" (3). In most of the discourses that have contributed to the establishment of these traits, we can detect the rhetorical use of transparency as a critique-resistant justification for a series of measures that displace-and sometimes replace-questions of ethics and fairness with questions of efficiency and productivity. And yet at the same time, transparency has gained momentum as a discursive device for evoking longstanding democratic ideals such as fairness, equality, and social justice. To put it another way, transparency has become a sort of political proxy for a cluster of nebulous values that seem to be under increasing demand in the face of an extended and globalised stage of neo-liberalism. Transparency promises an increase in accountability, a reduction of secrecy, and the exposure of the intricacies of power. And yet at the same time, it enlivens defences for the very mechanisms that embody power in late capitalism: the digital bureaucracies, intuitive interfaces, automated algorithms, minimalist looks and carefully designed "background" technologies that colonise the fringes of our awareness, rendering consumption frictionless, circulation seamless, and production unobtrusive. As Han has put it, rather boldly: "whoever connects transparency only with corruption and the freedom of information has failed to recognize its scope. Transparency is a systemic compulsion gripping all social processes" (2). Because of its ability to express the desire for free flows of information, as well as the will to control and administer their circulation, transparency has become a crucial notion for understanding contemporary political and economic struggles for power. However, this notion carries with it a far more complex semantic load than it might appear at face value.

Although the most extended semantic use of transparency today can be summarised as "access to information for the sake of accountability," the term has a much more elusive and conceptually dense history that it is frequently acknowledged. Transparency not only has a longstanding historical tradition in the cultural imaginary of the Western world, but it has also amassed a wide variety of uses-including domains as variegated as politics, governance, media, communication, technology, sociology, and cultural theorywhich adds considerable difficulty to any efforts towards disambiguation. In the context of governance, for instance, transparency refers to the idea that citizens should have the right to see the operations and activities of those in power or to a degree of collaborative decision-making, which is usually contrasted against models of centralised authority or vertical hierarchy. In institutional discourses, it usually refers to a certain willingness and ability of partners to disclose and share information that can increase accountability -the ability to trace back actions to a source. These uses emphasise the pole of "visibility." But there are other uses that emphasise the pole of invisibility. In the tradition of phenomenology, for example, the capacity for minds to be directed toward the world (intentionality) is accompanied by an inability to reflect on this very process (of transparency), so that the contents of minds are always something other than itself-or in softer versions, making it difficult for individuals to focus simultaneously on the objects of perception and the act of perceiving itself (Mohanty 75-76). In semiotics, the standard definition of a sign treats it as an entity "whose presence or occurrence indicates the probable presence or occurrence of something else" ("Sign"), an indication which, in order to be effective, depends on a certain degree of transparency (Lofts 146). In certain technological discourses, we also find the notion of "disappearance in use," which refers to the idea that, as Donald Norman puts it, technology is "our friend when it is inconspicuous, working smoothly and invisibly in the background" (115). In this context, Kettley has defined transparency in the following terms: "Also known as disappearance, transparency is largely considered the hallmark of good interaction design, wherein the user is able to complete tasks without cognitive interference caused by the interface" (37). This has been an influential aesthetic consideration for technological design, since, as Duchastel notes, "doing away with the interface itself is, after all, the ultimate in the quest of transparency that drives all HCI design” (332). In order to go beyond these different uses, I will now turn to the conceptual commonalities that link them together. 


\section{Transparency from a Conceptual Perspective}

As German conceptual historian Reinhart Koselleck points out, "a discourse [always] requires basic concepts in order to express what it is talking about" (65), some of which might end up becoming deeply embedded in our vocabularies-regardless of their original sources, inflections, or descriptive capacity. And as far as ideology is articulated and maintained through discursive means, it thus "makes sense to examine ideologies in terms of the basic concepts they contain" (Freeden 4). This task can both clarify the internal logic of a given ideological formation, and tell us something about the intricate relationship between discourses and its constituent concepts. Transparency is not an easy concept to theorise about, however, since it has come to signify an extensive and heterogeneous array of objects, processes, technologies, and practices (Hood; Gupta; Birchall). This becomes even more complicated if we attend to its etymology since, from its root, transparency implies the paradoxically simultaneous coexistence of visibility and invisibility. As Hansen, Christensen, and Flyverbom note, "the etymological roots of transparency essentially allow for either understanding, that is, to 'show light through' and to ... 'come into sight"' (118). As it transmits light, transparency provides a degree of information, and yet at the same time, it conceals the very thing that stands in the middle between emitter and receptor (the "something" that allowed the passage of light), which means that it can also simultaneously refract, diffract, and scatter some of this light. Transparency is both barrier and passage; it designates a threshold, an "in-between" and is thus an inherently ambiguous notion.

From a cognitive linguistics perspective, transparency is what Lakoff and Johnson call an "ontological" metaphor: a metaphor that imposes characteristics of physical objects on our experiences, in order to help us grasp more abstract ideas. A cognitive approach to metaphor (considering mental, not simply neurological processes) sees metaphors as expressions of more fundamental conceptual arrangements that involve mappings from "source" domains to "target" domains-or in Richards' (1936) original terminology, involving a "vehicle" (an entity in possession of an attribute) and a "tenor" (another entity to which this attribute is ascribed). From this perspective, and despite all of its various contingent associations, the concept of transparency is at its core, a visual metaphor. This metaphor carries the sense of motion and luminosity from the "source" domains of vision and three-dimensional space, into the "target" domain of abstract ideas. As Sweetser (1990) has shown, "our mental-focusing abilities are described by vocabulary drawn directly ... from the domain of physical manipulation, as well as by vocabulary from the domain of vision" (34). This close correlation between seeing, knowing, and grasping, situates transparency as a preamble-and gateway-to a specific will to competence. When we conceptualise knowledge as vision, all the words associated with the semantic constellation of vision are instantly allowed to bare associations with the semantic domain of knowledge. And since our range of vision depends on the opacity and transparency of things, treating the extent of this scope as stand-in for the limits of our understanding, the activation of transparency not only makes it possible to understand things, but to keep them under control: "Vision gives us data from a distance" (39).

The conceptual history of transparency starts with Greek Philosophy (e.g. Plato's cave allegory, or the belief that "as sight is in the body, so is reason in the soul," from Nichomamachean Ethics). This conception shifted in order to incorporate the prevailing assumptions of Medieval theology (e.g. the treatment of light as an efflux of the divine spirit, or the lux vivens of St. Augustine). Then, the concept shifted once again, under the influence of rationalism and the scientific enquiries of the Enlightenment (e.g. the microscope and telescope as windows that can shine the light of reason into the unknown, or the association of the translucent glass of laboratory beakers with scientific neutrality). But perhaps the most important shift occurred when the concept was recalibrated in response to the aesthetic and epistemological challenges of Modernism (e.g. new forms of subjectivity, the rise of the public sphere, the recognition of a tension between structure and agency, the use of large panels of glass and steel as metaphors of openness to the gaze of the public). Here we might think of Rousseau's depiction of human experience in his Discourse on the Origin of Inequality: the ongoing attempt to manage the loss of an (imagined) original state of innocence and natural transparency, and to cope with (what appears to be) progressive forms of obfuscation resulting from ever-increasing forms of mediation seeking to uphold social order. As Starobinski (1988) writes, with 
respect to Rousseau's oeuvre, the obsession with authenticity that drives the desire for transparency goes hand in hand with a fascination for obstructions (and a phobia of secrecy).

Finally, transparency comes to express a cultural shift related to the pre-eminence of information as the guiding paradigm of social life under techno-capitalism. Throughout this long and convoluted history, this visual metaphor was slowly but increasingly tied to the following basic conceptual inference: SeeingThrough-Overcomes-Ignorance. This is the primitive core, or "semantic precursor" informing most of the contemporary uses of the concept. This conceptual precursor or semantic primitive signals discernibility while acknowledging the presence of an obstacle. As such, it has to do with a certain will to competency, capacity, or power, which can turn an obstruction into a conduit: it suggests that we can go from "middle" to "medium." Transparency now names the cognitive optimum in which all that is sent arrives safelywhether we conceive it as information going through a channel, or as photons travelling through space. We are aware that there is always something in between, an irreducible gap between object and subject-but we also believe we can, nevertheless (via technical and rational means), get across it.

This is what Birchall gets at (although from a more political perspective) when she says that the term transparency involves an "invisible discourse" (Radical Transparency 81): what she wants to emphasise is how "mediation is obscured by its status as a cultural signifier of neutrality" (82). What I would like to add to this, crucially, is that there is a genealogy of semantic uses that has been key to the construction of an association between transparency and an enabling awareness. As Sloterdijk explains, Western metaphysics was basically "an ontology of the eyes that emerged from systematizing an outer and an inner vision" (27), a kind of "meta-optics" or "optical idealism" (50) based on a "metaphysics of light" (52). For the longest time, this metaphorical use of light dominated most discourses about subjectivity, influencing the ways in which we conceptualised space: or how we locate ourselves in relation to what is perceived at each moment. In order to make sense of something, the subject-viewer "must stand at a clear distance to the visible object. Being spatially apart and opposite suggests the assumption of a gap between subject and object that has not only a spatial but also an ontological effect" (28). Here we can find the origins of the mystification of the "middle."

One possible perspective holds that mediation is an unavoidable feature of our technologically mediated meaning-making practices. On this basis, we could also argue that processes of automated mediation are an inevitable development of the ubiquity of our computerised system of global communications. But the autonomy of the middle-entrusting the decision of how the coupling of self and world is to be understoodcannot be explained through mediation itself, and is not a settled matter. It was, and still is, one of the central problems of modernity, its main source of angst. How are we to interpret the simple yet puzzling fact that our means to perceive and describe the world do not grasp all of it, and may frequently "misrepresent" it? "There undeniably exists a specific thickness to things that prohibits us from seeing every feature of them simultaneously, making us speculate on the relationship between what is hidden and what is shown" (Brouwer, Spuybroek, and van Tuinen 7). The traditional epistemic gesture since the Greeks has been to interpret this thickness as something that muddles or conceals the essences of things-the ultimate, innermost truth about their existence. And from there, to distinguish between an ontological core as it is in and by itself, on the one hand, and the way in which that core shows itself to us, on the other. And the very moment in which we start talking about appearances, we are already positing another side to things-at best veiled, at worst inaccessible-another dimension, a deeper level, something that is not exhausted, something that resists apprehension. This simple idea is what lies at the fundamental intertwinement of politics and aesthetics, sustaining an agonistic clash between competing perspectives that demands some form of resolution or consensus. Transparency is another name for the dominant epistemological thread crossing the Enlightenment, the rational light of Aufklärung that believes in the disentanglement of the thickness of things-and promises to release us from self-imposed tutelage (Kant 33)-by the light of the mind. Under this cosmovision, appearances are seen as intermediate obstacle, while access to their underlying "truth" is reduced to a mere technical problem awaiting to be solved.

Though from a logical standpoint transparency is inherently ambiguous (both presence and absence), its contemporary discursive articulations have exploited the see-through metaphor in order to resolve this tension and imply a positive sense of immediacy. This combination of semantic ambiguity and 
metaphorical force makes transparency an exceptionally powerful rhetorical device that can mobilise and shape the cultural valence of its associated terms (openness as something inherently desirable, and secrecy as something intrinsically negative). This is frequently achieved through a sense of authority derived from gaining access to a level of information that is framed as being "not readily available"-as if peeking underneath the veil would grant us access to the truth. It executes a performative conflation between disclosure and facticity. Transparency becomes ideological the very moment in which it starts functioning under an abbreviated version of the aforementioned metaphor: the much more familiar and inconspicuous promise of Seeing-is-Knowing. When incorporated into arguments that follow an economic logic-such as those of neoliberal politics-the tension between invisibility and visibility takes the form of a scarcity-abundance binary: lack of information is seen as a marker of ignorance; and thus, so the logic goes, an abundance of information "must" then lead to knowledge.

As Murphy and de la Fuente emphasise, Capitalism's stylistic and affective cycles are just as important as economic cycles (2). And these cycles are all about forming odd-couplings: at the very core of any aesthetic relationship, we find a "distinction-complicity" (5), or a way of negotiating a transition between opposing qualities (Michelsen 67). With its attentiveness to cross-domain conceptual mappings and substitutions, a conceptual metaphor perspective allows us to grasp these cycles while retaining the insight that "the aesthetic faculty is a cognitive faculty for seeing one thing as another thing (emphasis added)" (Murphy and de la Fuente 6). As we move from an economy of information to an economy of attention, or put differently, when information becomes so abundant that the focus shifts towards competition for our cognitive resources (Shapiro and Varian 6-8), this "standing for something else" becomes exceedingly important: no matter how pertinent a given message might be, it still needs to be interesting (Murphy and de la Fuente 8). In times when emergent patterns of collective attention are able to determine the kinds of information that will be produced and consumed (Ciampaglia, Flammini, and Menczer par 1), aesthetics becomes fundamental for operations of framing content, which in turn are vital for aligning attention with commercial interests (Lanham).

\title{
Ideology as a Form of Transparency
}

\begin{abstract}
"I don’t much care if you call it ideology or not. What matters is not the terminology but the conceptualization (emphasis added). The question of the relative power and distribution of different regimes of truth in the social formation at any one time-which have certain effects for the maintenance of power in the social order-that is what I call 'the ideological effect”' (Stuart Hall 136).
\end{abstract}

The Western tradition tends to believe that transparency means knowledge and that knowledge is goodbecause it "enlightens." This epistemological attitude reaches its peak with the modern theory of information, encapsulated in Nobel laureate Joseph Stiglitz' assertion that 'transparency is just another name for information" (22). But although transparency involves the production of information, it is not information. Its very existence is tied to interpretations, narratives, and documents (e.g. hard drives, websites, bank account statements, financial reports, policy papers, opinion polls) that necessarily involve de-contextualisation and re-contextualisation. By effacing the fact that meanings do not precede the objects-and narratives-that convey them, calls for transparency are able to conceal the level of control over communication. Furthermore: for every measure to reveal or disclose, a countermeasure to bypass it can be put in place (think of politicians closing deals under the table, or informers going back to analog practices in the face of digital surveillance). This realisation has prompted some debate among scholars that have sought ways to explain how is it that demands for more transparency can, in fact, lead to a paradoxical lack of transparency in practice. While philosopher A. C. Grayling poses "complete transparency" as the best solution for recuperating citizens' lost trust on representative democracy, philosopher Onora O'Neill (2002) has argued that an increase in transparency can also cause "a flood of unsorted information and misinformation that ... may add to uncertainty rather than to trust" (72). In fact, it can even end up encouraging dishonesty: becoming hyper-conscious of their every word being 
caught on publicly accessible records, individuals might opt to "massage the truth" (73), aligning their opinions with what they perceive to be the safest or most popular position.

One way of explaining this paradox is to be found in concepts of misrepresentation and manipulation, such as Vujnovic and Kruckeberg's notion of "pseudo-transparency," which they define as "a set of strategic actions, ... through which organizations attempt to appear transparent by creating a sense of transparency (emphasis added), rather than by being truly transparent to their diverse publics" (122). Such explanations, however, operate under the traditional logic of propaganda: although they aim at demystifying semantic machinations and media manipulations, they leave the belief in transparency as a vehicle for authenticity untouched. Under this perspective, access to objective information about matters of fact would still be possible-all we have to do is find ways of discerning between "real" and "pseudo" transparency, and then trust would be restored. Others such as Mark Fenster have complicated these claims by emphasising transparency's inherent Janus-faced nature, pointing out that the same impulse compelling transparency also drives secrecy: control over information. Closer to this latter line of reasoning, I would argue that the paradox of transparency does not so much point to a struggle between different uses of the word, but is better understood as a manifestation of the internal structure of its underlying concept: the ambiguous co-existence of visibility and invisibility. By examining this paradoxical superposition of states, we can arrive at a different conception of how transparency operates today.

This operation has to do with a process of suspending the "how" for the sake of the "what," or in other words, to suspend the mode of deriving meaning, for the sake of the content of that meaning. This conceptual use of transparency combines awareness with a movement of "pointing-to-somethingother-than-itself." What I want to suggest, is that this is not just "another use" of transparency, but a more precise indication of the conceptual operation of the semantic category "transparency" in relation to ideology. And since Ideology is, in its most succinct formulation, "meaning in the service of power" (Thompson 56), then any critique aimed at it has to be able to say something about the crucial problem of ready-to-hand meanings-meaning that is too close to be "seen." In words of Foucault: the role of critique is not to expose what remains hidden, but rather making visible that which is "so close, so immediate, so closely related to ourselves that we do not perceive it" (540-541).

By adding the crucial dimension of distance to transparency, we can recuperate some of its critical potential. This would prevent us from forgetting the simple yet crucial fact that claims or ideas that were once novel, controversial, and arbitrary, can be incorporated into the cultural imaginary, turned into unquestioned assumptions, and become part of the "common sense" of a given culture. Discourses that are instrumental in installing and sustaining certain normative ideals for the benefit of one social group over the rest, we tend to designate as ideological. Roland Barthes' description of "myths" (the safeguarding of ideology by way of the active replication of dominant cultural stories), Pierre Bourdieu's reformulation of the concept of "doxa" (the perpetuation of ideology through the enactment of the distinction between what lies inside and outside of our social debates) and Antonio Gramsci's notion of "hegemony" (the preservation of ideology through won consent and the absorption of opposing perspectives within the matrix of dominant cultural norms) are some of the most notorious examples of theoretical efforts that sought to understand the mechanisms that attempt to sustain ideology over time (Ott and Mack). Useful as these approaches may be, they nonetheless soon encounter a limit-one that might be hinted at by way of a combination of all three: What if the dominant cultural story of the limits of the thinkable and the sayable is precisely the way in which contemporary ideology is able to absorb and incorporate dissent?

In his Marxism without Guarantees, Stuart Hall has argued convincingly that dismissing Marx's remarks on ideology on the basis of an implied reductionism in the term "false consciousness" would be counterproductive. While he did overemphasise its mystifying features, he did so mainly because he used the term ideology to refer to the manifestations of bourgeois thought (an idealism divorced from materialism) which he was combatting at the time. A more contemporary relevant way of understanding the "distortion" of ideology would thus be in terms of a limitation: as the inability to recognise the axioms that ground its categories. It "distorts" insofar it makes it more difficult for us to see the way in which the sphere of production organises social relations. In this way, it drives attention away from the level where 
the asymmetry of power is rooted-making us focus instead on the level of market exchange (where it is much more easier to maintain the claim that participants are "free" or "equal"). And yet the problem is not only that the ideology of transparency "distorts," but that it is able to operate precisely by pointing to this "distortion," feeding itself in its denunciation.

To this respect, Laclau and Mouffe have argued that the traditional understanding of ideology as "false consciousness" has perpetuated the belief that ideology conceals a "positive essence." This adds to the confusion since it assumes that this "essence" could somehow be directly perceived as soon as the ideological "veil" gets lifted. What this perspective usually fails to take into account is the tacit, implicit, and unspoken social norms that constitute a crucial yet invisible dimension of what we conceive to be a thing's "identity." Rather than defining false consciousness as the "distortion" of an "underlying essence," they suggest that we approach it as a kind of forgetfulness of the fact that the elements in discourse do not necessarily reflect natural practices, but in fact respond to transient, historicallybounded, and particular interests that do not have any necessarily self-evident connection with whatever it is we might imagine lying "beyond" (or below, or across, or behind) discourse. Thus, we might say that a central aspect of all ideologies is to be found in the operation of excluding the recognition of its own conditions of possibility. Hegemony would then describe the successful outcome of such an operation, insofar it expresses the "socio-political capacity of a ruling class to construct a system of legitimization" (Filippini 18), aligning consent with the reproduction of an order that facilitates its supremacy over the rest. Though the dominance of a given social group over others is ultimately carried out through the direct exercise of power (or the threat of it), a more indirect form of power (or leadership in Gramsci's terms) over its own "allies" is nonetheless necessary. And this softer power actually precedes the more direct power of material force over its "enemies." This alliance cannot succeed without a set of goals that are broad enough to incorporate (at least formally) the goals of those under subordination. In describing this strategy for securing expansion, Gramsci talks about an "educational relationship," by which consent needs to be "cultivated," otherwise, the dominant ideology (as any other with universal pretensions) would eventually succumb to the weight of its own internal contradictions. And the way in which the ideology of neoliberalism has been able to balance its own internal contradictionsnotably, an inescapable tension between an injunction to embrace the risk of individual freedom and a reproduction of the desire to feel "at home" in the world-is to both introject and appease them through the management of the ways in which the meaningful is registered on our senses. The tension between spontaneity and discipline can only be resolved through aesthetics, which is precisely why "aesthetic values [have] become tools of capitalist cultural domination" (Kirkpatrick 156). And this is nothing short of a paradox.

When it comes to Žižek's own take at transparency, he says that "the paradox is that ... the production process, far from being the secret locus of the prohibited, of what cannot be shown, of what is concealed by the fetish, serves as the fetish which fascinates with its presence" (102). Here the paradigmatic cultural product would be the "making off" that accompanies the movie, or perhaps the television show about magicians revealing other magicians' magic tricks, or the ironic advertisements that make fun of their own raison d'etre-profit. The point being that these "insights" into a given productive process no longer work towards dispelling their illusions: they do not give us any better understanding of the "how" or "why" of its operation; if anything, they merely perpetuate the distance between both. By deciding how, when, and to whom something will be disclosed, any subversive edge is tamed in advance. This amounts to a kind cancellation of the potential for critique; a pre-emptive strategy that reduces the affective intensity of the "a-ha" moment. The cultural gesture of exposing the inner mechanisms of how the world "really" works has become the very way in which the concealment of the mode of production is carried. Under this perspective, we can say that ideology today has embodied the logic of transparency itself, insofar as it operates as a "vanishing mediator," or as Slavoj Žižek has put it, a "founding gesture of creating difference, which must sink into invisibility" (275). 


\section{Transparency as Aesthetic Category}

As Baudrillard insistently denounced, the operation of transparency has an irredeemable aesthetic dimension to it: "This is what transparency means: the forcing of the whole of the real into the orbit of the visual (of representation) ... [to a point where it] takes the gaze hostage" (The Intelligence of Evil 73). The aesthetics of transparency is based on the production of mappings that insist on treating reality as something accessible and penetrable. It operates first by establishing "a binary opposition between interiority and exteriority and [then it] privileges the external or visible surface" (Hall, 321). The proliferation of this aesthetic form can be seen at work in the migration of security cultures from restricted areas to checkpoint zones, and from these borders or liminal points into everyday public spaces. Networks of AI-augmented CCTV cameras, biometric identification, full-body scanners and other techniques of screening, inspecting, and monitoring are moving from airports to schools or shopping malls, normalising surveillance and selfexposure. Simple measures such as transparent plastic bags replacing rubbish bins at train stations, or the use of Ziploc bags for carrying toiletries through airports (Hall), express the everydayness of this logic. The point to emphasise here is that the desirability for transparency needs to be sustained by periodic returns to figures of the opaque and undocile other (342). From the condemnation or negative portrayal of facial concealment (e.g. the controversial ban on the burkini in France, or the choice to remain anonymous at public manifestations) to a disdain towards social media lurkers-members of an online community who read but do not frequently post (Dennen 1625)-the positive cultural valence of transparency relies on the scorn of its obverse. As Schinkel puts it: "the veiled subject is considered intentionally illegible ... treacherous, untrustworthy" (191). This might serve as a fair illustration for showing that transparency is ideological. But it doesn't point to the way in which ideology can become transparent.

Van de Port has argued, in a fashion that resonates with Bolter and Grusin's notion of hypermediacy, that the "unmasking" of the medium can also produce "its own sensations of immediacy" (76). And he locates this reality-effect in style-the iterability of modes of framing experience with a distinctive preference either for veiling or for unveiling the process of mediation. Before setting out to reveal what is it exactly that the secret holds (what we may call, its 'finite' content), we already assumed the existence of a secret: we already "sense" secrecy (what we may call, its non-finite form). The combination of a given logic of interpretation along with the means of interpreting (which may be linguistic, technical, political, and so on), 'supersedes' or 'surpasses' the content, insofar it sets up the modality of the secret's disclosure-the way in which it imposes itself, its social function, its mode of proliferation. As Mazzarella put it, following Derrida, mediation mediates, but it can also produce a "fiction of premediated existence" (357). It is in this sense that ideology achieves transparency-it becomes an empty Trojan horse. The cultural range of such a logic goes from simple objects made out of see-through acrylic or Plexiglas (such as the transparent model of the handheld game console Game Boy Play it loud! released in 1995), to dezukai, a specific style of performance within the traditional Japanese puppet theatre bunraku, where the puppeteer does not hide behind dark robes, and instead incorporates the visible manipulation of puppets as part of the performance (van de Port). In these examples (though in obviously different degrees), the trick lies not in the ability to show something else while concealing something else, but in framing unconcealment. It is here that, as Taussig put it "the mystery is heightened, not dissipated, by [way of] unmasking" (273). For this to really work, attention needs to be guided. And this is the role of aesthetics.

Modernists believed that once freed from ornament, Design would be able to fully express the true "spirit of the age" (Parsons 61). This somewhat counterintuitive idea can only make sense in a moment in which the accumulation and availability of "older" style becomes so pervasive, that the only way to express any significantly recognisable historical identity is to develop a non-style, reducing form to its very minimum: function. This was a culminating stage in the naturalisation of the seemingly innocuous idea that what is good, is what is useful. However, we tend to forget that when we say "function," we are really saying the "proper" (Parsons and Carlson), official, or authoritative function, a social convention distinguishing between accepted and improper uses-as well as the "distinction-complicity" informing our sense of familiarity and abnormality. Expectations about functionality provide a crucial hinge between the aesthetic and the epistemic, since they lie at the core of unreflective behaviour under capitalism. 
From its very beginning, "bourgeois culture faced the enormous task of transferring the sublime from the absolutist to the democratic state" (Sloterdijk 23). This task required an aesthetic ideology that could advance submission in spite of resistance, making subjugation palatable. And this-just as Gramsci pointed out-required recruiting everyone. But although mass culture succeeded in democratising the sublime by making the beautiful central to its project, the price to pay was a sort of inversion: "everything is beautiful now, except art, and everything is critical except art criticism" (25). The sublime retreated into the nonbeautiful and non-understandable, sinking down into a ghostly non-presence. And at the same time, the style-less style of Modernist functionalism became the blueprint for the ideological strategy of future neoliberalism: a feeling of epistemic neutrality that could turn its internal contradiction into a productive advantage. As Murphy puts it: "The short of it is that modern capitalism of the past two centuries has proved astonishingly successful in a material sense because it absorbed into its core the non-material spirit of paradox and analogy" (49). This capacity to harness contradiction is precisely what transparency accomplishes, providing a way for ideology to jettison any associations with coercion, and to present itself as a spontaneous sociocultural consensus. Under the pretence of usability and the belief that attention is a scarce resource, it has managed to elide the fact that rules of use-however tacit they might appcan notnnot divorce themselves from the sensuous representations and aesthetic categories that animate them.

As Hanna Arendt (qtd. in Ngai) has argued, Aesthetic categories are not merely perceptual, but can also be conceptual (104). Similarly, Sloterdijk has called conceptualisation a "fourth" dimension of the aesthetic (coming after the sublime, the beautiful, and irony) (26). However, the ways in which we relate to their conceptual dimension can differ considerably from category to category-and from period to period. In his Critique of Judgment, Kant put forth the idea that aesthetic judgments require us to imagine an impersonal voice speaking (qtd. in Chaouli 60), so as to go above the awareness of the fickleness of our personal appraisals and individual tastes, and into the certainty of an assessment of qualities that pertain to "the thing" being regarded-at least in the form of a correspondence with an imagined "other." It is almost as if aesthetic discourse "were at the deepest level a discourse about its own intersubjective and affective dynamics" (Ngai 41). But while some aesthetic judgments are able to make us aware of the constructed nature of their appeals to objectivity by pointing to their argumentative (and social) recourse to extraaesthetic values, other aesthetic judgments "not only seem incapable of acknowledging this underlying state of discursive conflict but also actively work to conceal it” (44). For Ngai, the aesthetic category that makes this covert aspect of "passing performativity under the radar" most explicit for us is the interesting, since it is perhaps the only one that allows us to openly discuss issues of pleasure and value in direct relation to our social matrix. And although Ngai does not posit any aesthetic category at the opposite pole of the spectrum, I would argue that this place is occupied by transparency-concealing by way of showing. Though for Ngai the interesting can serve as a compelling reminder of the asymmetries of power underlying our system of aesthetic judgments, the work of transparency is to elide any trace of them.

As an aesthetic category, transparency has to do with a kind of "felt certainty." And at first glance, it might seem that this category is similar to what Sianne Ngai has described as the aesthetic category of "the interesting." This similarity would be grounded in the fact that both of them deal with the same tension between familiarity (the safe) and newness (the potentially dangerous), or as Epstein puts it, with the tension between the "alterity of the object and reason's capacity to integrate it" (230). Things are interesting to us to the extent we deem ourselves capable of incorporating novelty to our existing schemas. If something feels too strange or atypical it would lose that interesting quality (giving us the category of the uncanny), and if it feels too common it might be simply deemed boring. Another similarity, is the fact that one of the most distinct features of the aesthetic category of the interesting is its conceptual indeterminacy, which would also make it a seamless category for "linking aesthetic judgments to nonaesthetic judgments" (13). This is why she describes the interesting as "the 'styleless' style of the distributed-media" (14) through a genealogy that went from an appearance of eclecticism to one of pure difference in information. This conceptual indeterminacy, coupled to a feeling of certainty, is precisely why transparency is able to serve as an optimal ideological vehicle: it transforms it into a meta-aesthetic category that can sustain itself by absorbing all oppositions, morphing its own shape in order to fit them within. But while transparency shares this same structure of inner "emptiness"-the capacity to serve as a carrier for something other than itself-it can be 
distinguished from the category of the interesting by one crucial aspect: transparency involves a particular will to realism. The reality effect of transparency does not bypass relativism (an acknowledgement of different points of view) so much as confine it to the epistemic level (detaching it from an assumed, deeper ontological level-one that nonetheless is never disclosed). It incorporates different styles (or modes of representation) while simultaneously declaring: yes, objectivity does exist, and it can be attained without recourse to representation. But since there is no deeper floor lying beneath its appearances, this promised objectivity can only be found in others-in our intersubjective affects (or their translation into an imagined public opinion). In this way, the ontological effect of realism is achieved by a tautological sleight of hand.

This "trick" exhibits Capitalism's realisation that the most primordial level of belief is to be found in inter-subjectivity: the fact that there's someone else out there (whoever she might be) that also believes (in whatever it is that I believe). The most basic pre-requisite for a subject to hold a belief, is for her to imagine that she is not alone in that belief: common belief precedes individual belief. If I believe in something while simultaneously thinking that I'm the only one believing that, then that belief immediately enters the category of the imaginary. Reality (and realism) requires mutuality: it requires trust in a shared conviction-a minimal degree of intersubjective recognition. Approaching this rather Hegelian perspective in terms of meaning, we could follow Wittgenstein in his statement that "obeying a rule" is a practice: "it is not possible to obey a rule 'privately': otherwise thinking one was obeying a rule would be the same thing as obeying it" (81). Compliance with a norm (or the assuredness of having grasped a sense) is a public matter: it involves shared customs and the recognition of the modes of acting of others. Likewise, the feeling of certainty in meaning emerges not from my interpretation of the content expressed by some "rule," but from acting in accordance to the ways in which a specific community of speakers perform acts of acceptance and disapproval. Or, as Žižek puts it with his distinctive Lacanian inflection: the subject supposed to believe is the "constitutive feature of the symbolic order" (106) (the order we ordinarily call "our world"). The deferral of certitude-the transference of this responsibility to others, is unavoidable. Belief sustains itself through a circuit of displacements, and can only thrive in the "shadowy domain between outright falsity and positive truth" (108). We say: someone else will do it for me-and then we buy some time. Verification is a promissory ote, and a binding pact.

The important point is that there is no reason why this cannot be felt or experienced as an absolutely freeing experience: our submission to the norm can also liberate us from the burden of having to provide rational validation for our beliefs. "The very awareness that the Other regulates the process in which I participate, sets my mind free to roam, since I know I am not involved” (Žižek 110). Whereas at one point in time a painted canvas might have been considered irrefutable proof and evidence of a "style," today, in our heavily mediated networked environments, it is other people's reactions to a given aesthetic experience which have become "the most reliable sign of the authenticity of contemporary aesthetic experience" (Ngai 28). And this indirect mode of certainty constitutes a highly pleasurable experience. We enjoy the "likes" of a post more than our recollection of the event itself. We go to the videos with more views, we read the stories that become viral. In such a scenario, "the minimal, least obtrusive claim of value possible for the cultural object" (110) is not the interesting, but the transparent: before we can even decide whether something deserves our interest, we have already placed ourselves in relation to it-we have already qualified our distance to it. We have already felt that having more information is something intrinsically worthy of pursuit. And yet, we have already felt the pressure of "information overload." We want to store, to accumulate. We want to save time. And in the process, as Harcour has rightly pointed out, we have become joyfully complicit in our own data-driven exploitation.

\section{Concluding Remarks}

Transparency has become such an uncontroversial value because it pretends to "regulate only the form, not the content, of social interactions: a principle that purports to be neutral, all the while imposing a morality upon both public and private life" (Alloa 47). The problem is not that, as Bauman put it, "what is easily legible or transparent for some, can be dark and opaque for others" (29). It is not too difficult to agree with 
this statement. But this is not the point. We could say that efforts to make the world more "transparent" should not be detached from both the means to, and the interests for, making it legible. This would be a bit more precise, but would still not get to the point. We could say that transparency should be treated as ideology, because it works towards effacing the fact that meanings do not precede the narratives that convey them. This is better, but still misses the point: in spite of this, transparency would still remain sheltered from critique. Why? While the pretence to objectivity is easily refutable-anyone can contest a claim to objectivity-transparency appeals to inter-subjectivity: through its attempt to pass as a meta-aesthetic value, it puts itself beyond the reach of critique: we all need at least a minimum level of transparency in order to communicate effectively. The point is: the ready-made debunking of ideology is an ideology in itself-or as Vattimo already put it, from a different angle: demythologisation can constitute a myth in itself. Under this perspective, transparency is better defined not as information, but as surplus-meaning-the very unconscious dimension of ideology (Eagleton; Freeden, Ricoeur). It is a socially articulated organisation of meaning that involves the resolution of a lower-level cognitive dissonance through a higher-level of metainformation, exploiting a tension at the epistemic level and hiding the axiological supplement that comes to resolve this tension.

The see-through metaphor of transparency does not merely oppose terms (the visible and the invisible), it conveys the implicit authority of one of the terms (presence) and thus polarises the balance of any analogy coupled to it. We can illustrate this formula in the following manner: "There" (what's present for the observer) is first turned into "there for" (for the sake of) -(it is given a purpose), and on a second movement, it becomes "therefore" (it is turned into a justification for the already given purpose), which then obtains the status of being "natural." In this sense, we can say that it is an "empty" signifier; it does not possess content, but rather structures one specific location from where to look at the rest of symbolic landscape, which is to say, it structures other signifiers in a specific way. It makes us think that we are dealing with things, when in fact we are dealing with socially constructed values. When harnessed for the sake of rhetoric, transparency can thus resolve the inherent contradictions of neoliberalism by "superseding" the level of content and setting up the modality of disclosure in advance. If anything, transparency names the operation by which the normalisation of mediation is accomplished. It internalises an instrumentalist will that is paid for by a diminishment in the perception of the intermediary agencies that regulate our social relations.

Upholding value-neutrality is far from being a sign of objectivity, and should not be treated as more than a symptom of an operation guided by an undeclared set of values. Correspondingly, the task of critique thus needs to incorporate forms of making explicit the normative infrastructure of our conceptual assumptions-if the very conceptual scaffolding of one of our key contemporary notions has been put to the service of ideology, we cannot simply assume that critical efforts that mobilise this notion are impervious to the neoliberal machinery. As Zambrana rightfully comments: "Neoliberal resignification presses us to rethink critique in light of its normative ambivalence" (96). Treating ideology as a mere distortion of reality misses the point, and makes us fall into a self-referential paradox: there is no vantage point from where to look at the operation of the system, there is no "outside." The point is not to try to avoid ideology in order to access Truth, but rather to work towards constructing new concepts that can succeed in making our epistemic construals explicit.

We should be careful in using transparency as a device for demystificaion, since it is much more accurately described as its exact opposite: a promise of access to the real that has become a crucial element in an ongoing fetishisation of the medium. Thus, it becomes imperative that we work towards developing a critique of transparency that takes its ideological dimension seriously. As Andrejevic puts it: "the target of ideology critique-of critical theory generally-in this savvy era ought to be not the false mask that covers the obfuscated reality ... but the function of the promise of access to this reality" (215). What continues in the wake of "false consciousness," is a need to assess the role that specific techno-cultural assemblages play in the historical re-structuration of the subliminal-the threshold that modulates how, when, and to which extent a particular codification of desire (a way of doing things is to gain enough conventional momentum as to be considered "natural"). This is still, the task of critique.

Before using transparency as the basis for a future-oriented politics, we need to inspect the conceptual architecture that supports its parasitic logic. And what this preliminary inspection shows, is not only 
that the impossible ideal of transparency is a form of ideology, but that at the same time, in order to be sustained, ideology today necessarily involves a form of transparency. A critique of transparency framed in these terms can offer us an interesting position from where to look at the ways in which ideologies are able to preserve their influence in spite of-or rather, precisely through-our very efforts to challenge them. Through the historical analysis of the conceptual foundations of transparency we can have a better sense of neoliberalism's-invisibility cloak; a slow yet determined effort towards the construction of better conceptual tools for making power visible.

\section{Works Cited}

Akerlof, George A. “The Market for 'Lemons': Quality Uncertainty and the Market Mechanism.” The Quarterly Journal of Economics, Vol. 84, No. 3 1970, pp. 84(3), 488-500.

Alloa, Emmanuel. "Transparency: A Magic Concept of Modernity." Transparency, Society and Subjectivity Critical Perspectives, edited by Emmanuel Alloa and Dieter Thomä, Palgrave Macmillan, 2018, pp. 21-56.

---. Thomä, Dieter. “Transparency: Thinking Through an Opaque Concept.” Transparency, Society and Subjectivity: Critical

Perspectives, edited by Emmanuel Alloa and Dieter Thomä, Palgrave Macmillan, 2018, pp. 1-14.

Andrejevic, Mark. Reality TV: The Work of Being Watched. Rowman and Littlefield, 2004.

Arendt, Hanna. “Labor, Work, Action.” The Portable Hanna Arendt, edited by Peter Baher, Penguin Classics, 2003, pp. 178.

Baudrillard, Jean. Simulacra and Simulation. The University of Michigan Press, 2013.

--.. The Intelligence of Evil: Or The Lucidity Pact. Bloomsbury, 2013.

Birchall, Clare. "Introduction to 'Secrecy and Transparency': The Politics of Opacity and Openness." Theory, Culture \& Society, vol. 28, no.1, 2011, pp. 7-25.

Birchall, Clare. “Radical Transparency?" Cultural Studies $\leftrightarrow$ Critical Methodologies, Vol. 14, no. 1, 2014, pp. 77-88.

Bolter, J. David. Grusin, Richard. Remediation: Understanding New Media. MIT Press, 1999.

Brower, Joke. Souybroek, Lars. Van Tuinen, Sjoerd. Introduction: In the Thick of Things. The War of Appearances (pp. 1-11). V2_Publishing, 2016.

Chaouli, Michel. Thinking with Kant's Critique of Judgment. Harvard University Press, 2017.

Ciampaglia, Giovanni Luca. Flammini, Alessandro. Menczer, Filippo. The production of information in the attention economy. Center for Complex Networks and Systems Research, School of Informatics and Computing, Indiana University, 2014.

De la Fuente, Eduardo. Murphy, Peter. “Introduction: Aesthetic Capitalism.” Aesthetic Capitalism, edited by Eduardo de la Fuente and Peter Murphy, Brill, 2014, pp. 1-9.

Dennen, Vanessa Paz (2008). “Pedagogical lurking: Student engagement in non-posting discussion.” Computers in Human Behavior. 24 (4): 1624-1633.

Derrida, Jacques. Of Grammatology. Johns Hopkins University Press, 2016.

Eagleton, Terry. “The Ideology of the Aesthetic." Poetics Today, vol. 9, 1988, pp. 327-38.

Epstein, Mikhail. The Transformative Humanities: A Manifesto. Bloomsbury, 2012.

Fenster, Mark. The Transparency Fix: Secrets, Leaks, and Uncontrollable Government Information. Stanford University Press, 2017.

Filippini, Michele. Using Gramsci: A New Approach. Pluto Press, 2017.

Foster, Hal. Design and Crime: and Other Diatribes. Verso, 2002.

Foucault, Michel. “La Philosophie Analytique de la Politique.” Dits et écrits, 1954-1988, vol. 3: 1976-1979, edited by D. Defert and F. Ewald. Gallimard, 1994, pp. 534-551.

Freeden, Michael. "Editorial: Ideologies and Conceptual History.” Journal of Political Ideologies, vol. 2, no. 1, 1997, pp. 3-11. Genette, Gérard. The Aesthetic Relation. Cornell University Press, 1999.

Geroulanos, Stefanos. Transparency in Postwar France: A Critical History of the Present. Stanford University Press, 2017.

Gramsci, Antonio. Selections from the Prison Notebooks, edited by Quentin Hoare and Geoffrey Nowell Smith). Lawrence and Wishart, 1971.

Grayling, A. C. Democracy and Its Crisis. One World, 2017.

Gupta, Aarti. “Transparency in Global Environmental Governance: A Coming of Age?” Global Environmental Politics, Vol. 10, no. 3, 2010, pp. 1-9.

Hall, Rachel. "Of Ziploc Bags and Black Holes: The Aesthetics of Transparency in the War on Terror." The Communication Review, vol. 10, 2007, pp. 319-346.

---.. The Transparent Traveler: The Performance and Culture of Airport Security. Duke University Press, 2015.

Hall, Stuart. On Postmodernism and ArticulaAnon: an Interview with Stuart Hall. Stuart Hall: Critical Dialogues in Cultural Studies, edited by David Morley and Kuan-Hsing Chen, Routledge, 1996, pp. 131-50.

-.-. "The problem of ideology: Marxism without Guarantees." Marx: 100 years on, edited by Betty Matthews, Lawrence and Wishart, 1983, pp. 57-84. 
Han, Byung-Chul. The Transparency Society. Stanford University Press, 2015.

Hansen, Hans K., Christensen, Lars T., Flyverbom, Mikkel. “Introduction: Logics of Transparency in Late Modernity: Paradoxes,

Mediation and Governance." European Journal of Social Theory, vol. 18, no. 2, 2015,pp. 117-31.

Harcour, Bernard E. Exposed: Desire and Disobedience in the Digital Age. Harvard University Press, 2015.

Hood, Christopher. "Transparency in Historical Perspective.” Transparency: The Key to Better Governance?, edited by

Christopher Hood and David Heald, Oxford University Press, 2006, pp. 3-23.

Isaacson, Walter. Steve Jobs. Simon and Schuster, 2011.

Kant, Immanuel. “An Answer to the Question: What is Enlightenment?." German Aesthetic and Literary Criticism, edited by

David Simpson, Cambridge University Press, 1984, pp. 29-34. Originally published in 1784.

Kirkpatrick, Graeme. Technology and Social Power. Palgrave Macmillan, 2008.

Koselleck, Reinhart. "A Response to Comments on the Geschichtliche Grundbegriffe.” The Meaning of Historical Terms and

Concepts, edited by Hartmut Lehmann and Melvin Richter, German Historical Institute, 1996, pp. 59-70.

Laclau, Ernesto, and Mouffe, Chantal. Hegemony and Socialist Strategy: Towards a Radical Democratic Politics. Verso, 2001.

Lakoff, George and Johnson, Mark. Metaphors We Live By. University of Chicago Press, 2008.

Lanham, Richard A. The Economics of Attention: Style and Substance in the Age of Information. The University of Chicago

Press, 2006.

Mazzarella, William. “Culture, Globalization, Mediation.” Annual Review of Anthropology, vol. 33, 2004, pp. 345-367.

Michelsen, Anders. "The Visual Experience Economy: What Kind of Economics? On the Topologies of Aesthetic Capitalism." Aesthetic Capitalism, edited by Eduardo de la Fuente and Peter Murphy, Brill, 2014. pp. 63-88.

Murphy, Peter. "The Aesthetic Spirit of modern Capitalism." Aesthetic Capitalism, edited by Eduardo de la Fuente and Peter

Murphy. Brill, 2014, pp. 47-62.

Ngai, Sianne. Our Aesthetic Categories: Zany, Cute, Interesting. Harvard University Press,

O'Neill'neill, Onora. A Question of Trust: The BBC Reith Lectures 2002. Cambridge University Press, 2002.

Ott, Brian L. and Mack, Robert L. Critical Media Studies: An Introduction. John Wiley \& Sons, 2013.

Parsons, Glenn. The Philosophy of Design. Polity, 2016.

--.. Carlson, Allen. Functional Beauty. Oxford University Press, 2008.

Richards, Ivor Armstrong. The Philosophy of Rhetoric. Oxford University Press, 1937.

Rousseau, Jean-Jacques. Discourse on the Origin of Inequality. Dover, 2016.

"Sign." Oxford Living Dictionaries. https://en.oxforddictionaries.com/definition/sign. Accessed 11 Sept. 2018.

Shapiro, Carl. Varian, Hal R. Information Rules: A Strategic Guide to the Network Economy. HaBusinesssiness School Press, 1999.

Sloterdijk, Peter. The Aesthetic Imperative. Polity, 2017.

Stiglitz, Joseph. Keynote Address. Development Cooperation Forum: Achieving More Equitable Globalization (pp. 20-30). The Carter Center, 2005.

Starobinski, Jean. Jean-Jacques Rousseau: Transparency and Obstruction. Translated by Arthur Goldhammer. University of Chicago Press, 1988.

Taussig, Michael. "Viscerality, faith and skepticism: another theory of magic." Magic and modernity. Interfaces of revelation and concealment, edited by Birgit Meyer and Peter Pels, Stanford University Press, 2003, 272-306.

Thompson, John B. Ideology and Modern Culture. Polity, 1990.

Vattimo, Gianni. The Transparent Society. Johns Hopkins University Press, 1992.

Vujnovic, Marina, and Dean Kruckeberg. "Pitfalls and Promises of Transparency in the Digital Age." Public Relations Inquiry, vol. 5, no. 2, 2016, pp. 121-43.

Wittgenstein, Ludwig. PhilosopInvestigationsations. Translated by G. M. E. Anscombe. Basil Blackwell, 1958.

Zambrana, Rocío. "Paradoxes of Neoliberalism and the Tasks of Critical Theory." Critical Horizons, vol. 14, 2013, pp. 93-119.

Žižek, Slavoj. Less Than Nothing: Hegel and the Shadow of Dialectical Materialism. Verso, 2012. 